\title{
Poor newborn care practices - a population based survey in eastern Uganda
}

Peter Waiswa ${ }^{1,2^{*}}$, Stefan Peterson ${ }^{1,2,3 \dagger}$, Goran Tomson ${ }^{2,4 \dagger}$, George W Pariyo ${ }^{1 \dagger}$

\begin{abstract}
Background: Four million neonatal deaths are estimated to occur each year and almost all in low income countries, especially among the poorest. There is a paucity of data on newborn health from sub-Saharan Africa and few studies have assessed inequity in uptake of newborn care practices. We assessed socioeconomic differences in use of newborn care practices in order to inform policy and programming in Uganda.

Methods: All mothers with infants aged 1-4 months $(n=414)$ in a Demographic Surveillance Site were interviewed. Households were stratified into quintiles of socioeconomic status (SES). Three composite outcomes (good neonatal feeding, good cord care, and optimal thermal care) were created by combining related individual practices from a list of twelve antenatal/essential newborn care practices. Multiple logistic regression analysis was used to identify determinants of each dichotomised composite outcome.
\end{abstract}

Results: There were low levels of coverage of newborn care practices among both the poorest and the least poor. SES and place of birth were not associated with any of the composite newborn care practices. Of newborns, $46 \%$ had a facility delivery and only $38 \%$ were judged to have had good cord care, $42 \%$ optimal thermal care, and $57 \%$ were considered to have had adequate neonatal feeding. Mothers were putting powder on the cord; using a bottle to feed the baby; and mixing/replacing breast milk with various substitutes. Multiparous mothers were less likely to have safe cord practices (OR $0.5, \mathrm{Cl} 0.3-0.9)$ as were mothers whose labour began at night (OR 0.6, Cl 0.4 - 0.9).

Conclusion: Newborn care practices in this setting are low and do not differ much by socioeconomic group. Despite being established policy, most neonatal interventions are not reaching newborns, suggesting a "policy-topractice gap". To improve newborn survival, newborn care should be integrated into the current maternal and child interventions, and should be implemented at both community and health facility level as part of a universal coverage strategy.

\section{Background}

In low income countries (LICs), progress towards achieving Millennium Development Goal 4 - to reduce by two-thirds under- 5 mortality from the 1990 baseline - is being hampered by slow progress in reducing neonatal death [1]. The neonatal period is only $1 / 60$ of the first five years of life, but contributes $38 \%$ of the estimated 10.5 million under-five deaths which occur every year [2]. It is estimated that each year four million neonatal deaths occur, and almost exclusively in low income countries [3]. There is a paucity of data on newborn

\footnotetext{
* Correspondence: pwaiswa2001@yahoo.com

† Contributed equally

${ }^{1}$ Makerere University School of Public Health, Kampala, Uganda
}

health from sub-Saharan Africa, and few studies have assessed inequity in uptake of newborn care practices.

The World Health Organisation recommends improving care practices at birth in order to reduce neonatal morbidity and mortality. These have been described as essential newborn care (ENC) practices [4] and include clean cord care, thermal care and initiating breast feeding immediately or within the first hour after birth. These simple practices are critical for all babies in order to save lives, but also need to be fitted into a comprehensive newborn care package which includes skilled care at birth, care-seeking, extra care for sick and small babies, and skilled care at birth including resuscitation. Effective promotion of ENC at scale could significantly contribute to reducing the leading causes of newborn
C Biomed Central 
deaths in LICs, especially those due to sepsis/pneumonia, preterm births and tetanus [5].

To be effective, such evidence-based interventions need to be implemented within the continuum of care for maternal, newborn and child (MNC) care [5-7]. The continuum of care for MNC health has been defined as "access to care provided by families and communities, by outpatient and outreach services, and by clinical services throughout the lifecycle, including adolescence, pregnancy, childbirth, the postnatal period, and childhood [5-7]. An effective continuum implies that care of the mothers and babies at home, in lower level facilities, and in referral centres is adequately linked and is of high quality [5-7]. From a conceptual point of view, this is the ideal strategy, as its implementation would benefit both mothers and newborn babies [5]. However, given the high maternal and newborn mortality in subSaharan Africa, it is clear that there is either no adequate quantity and/or quality in the MNC continuum in these countries or it may be suggestive of the difficulties in its implementation.

Maternal and newborn outcomes remain very poor in Uganda. The total fertility rate is 6.7 , while the under five mortality rate is $137 / 1000$, the neonatal mortality rate $29 / 1000$, and maternal mortality ratio is $435 /$ 100,000 live births [8]. Antenatal care attendance at least 4 times is $42 \%$ and only $41 \%$ of deliveries are supervised. These poor indicators are despite the fact that ANC attendance at least once during pregnancy is at $92 \%$ [8] and $72 \%$ of the population is within $5 \mathrm{~km}$ distance of a health facility [9]. Although recommended in policy, in practice virtually no post-natal care exists.

Inequity in child health is high in Africa but few studies have assessed it with respect to newborn care. Mortality is higher and coverage is lower among the poorest, implying that addressing the needs of the poorest should be a priority for all programmes [10]. Analysing mortality and coverage by SES provides information that is hidden in national and even regional averages. It has been argued that when packaged, child survival interventions are less equitable, with children belonging to the poorest families consistently being less likely to receive preventive and curative interventions [11]. The aim of this study was to assess socioeconomic differences in levels of coverage of essential newborn care practices in order to inform programming and policy in Uganda.

\section{Methods}

\section{Study setting}

The study was conducted in the Makerere Universityoperated Iganga-Mayuge Demographic Surveillance Site (DSS) located in eastern Uganda, about $120 \mathrm{~km}$ east of the capital Kampala. The Basoga contribute about 10\% of the population of Uganda, but their practices are similar to those of other Bantu ethnic groups who are the majority in Uganda. Eighty percent of the population are peasants and live on less than US $\$ 1$ a day. An estimated $49 \%$ of women and $68 \%$ of men are literate (Iganga District Local Government 2008). Traditional birth attendants (TBAs) are significant actors in the provision of antenatal and delivery care in the district. At the time of the study, there were no specific interventions promoted to target the newborn, either at facility or community level. About 30\% of the DSS population lives in peri-urban settings with relatively better access to health care compared to their rural counterparts.

The DSS has a population of about 67,200 people in 65 villages, 18 parishes and 12,000 households. The household and community structures have been mapped using the Global Positioning System. Over forty locally recruited field assistants whose minimum education is upper secondary school level collect data from each household every fourth month and are supervised by a group of DSS staff from a central office. Village-based demographic scouts notify DSS staff of all deaths and births in the area as they occur on a continuous basis. The DSS area has 13 health facilities of which ten are government facilities including the district hospital, the other three being non-Governmental organisation facilities. The area is also served by over 120 pharmacies and private clinics. The neonatal and post-neonatal mortality rates in the DSS are estimated at 22.3 and 55.2 per 1000 live births, which compares very well with estimates for the entire region as reported in the national demographic health survey (24 and 50 per 1000 live births) [8].

\section{Study design and data collection}

This population-based cross-sectional study represents socio-demographic, SES, and antenatal and newborn care practices among Ugandan women with a baby aged 1-4 months $(\mathrm{n}=414)$. Socio-demographic and household SES information were collected in a separate survey a year earlier. Socio-demographic information, as collected from the DSS, included age, level of education, occupation, religion, tribe, birth order, and sex of the reference child. Household SES is represented by household assets.

The DSS field assistants underwent a three day training to use the survey tool which had been translated into Lusoga, the local language in the area. The training included piloting the tool among 25 mothers attending a postnatal clinic at the local hospital. The survey was conducted from March to August 2007. Mothers who had had a stillbirth (data not available) or a neonatal death (64 neonates) were not interviewed for this study. Data collected in this study included information about 
antenatal care (ANC) practices (attendance, place of attendance, number of visits made, HIV testing, birth preparedness, use of drugs to prevent malaria in pregnancy, and provider of ANC) and delivery (place, time of labour onset and type of attendant at delivery). Women were also asked about their experiences with ENC practices, including type of instrument used to cut the cord, type of material used to tie the cord, when the newborn was first dried and wrapped, length of time before the newborn was bathed the first time, whether any pre-lacteal feeds were given, length of time (hours/ days) before breastfeeding was first initiated, and whether the baby was exclusively breastfed during the first month of life. The quality assurance of data was through daily assessment via questionnaires filled-in by a supervisor; in cases of error or incompleteness of data, corrective measures were implemented immediately.

\section{Statistical analysis}

Data were entered using FoxPro and cleaned, linked with the DSS database, and then transferred to STATA, version 10, for analysis. For SES, we used the same group of context-specific assets used by the Uganda Bureau of Statistics. These items were screened for relevance, and reliability testing was done using Cronbach's alpha [12]. The final list included the number of sleeping rooms, type of floor material, type of roof material, wall material, fuel used for cooking and source of light. Other variables were households having or not having the following items: a radio, a sewing machine, an electric flat iron, type of bed, charcoal flat iron, a bed net, kerosene lamp, kerosene stove, car, tea table, refrigerator, television set, sound stereo, telephone, mattress, wheel barrow, cell phone and camera. These gave a Cronbach's alpha of 0.848 . Principal component analysis (PCA) was performed and the first principal component was scored to create an asset index that was used to group all households in the DSS into wealth quintiles [13].

Using the following twelve ANC/ENC practices, we calculated the mean and median number of practices accessed by the mother/newborn: ANC, tetanus toxoid, antimalarial use during pregnancy, HIV test, and insecticide treated net (ITN) use, anemia drugs, clean birth, facility delivery, safe cord care, optimal thermal care, good breastfeeding, and ITN after birth. The following composite outcome variables were then created: (i) Good cord care (defined as use of a clean cutting instrument to cut the umbilical cord plus clean thread to tie the cord plus no substance applied to the cord); (ii) Optimal thermal care (defined as baby put skin-to-skin at birth or wrapped at birth plus first bath after 6 or more hours); and (iii) Good neonatal breastfeeding (defined as initiating breastfeeding within the first one hour after birth plus baby given no supplements at all in the first month of life). These composite variables were then dichotomised to Yes (all practices present) or No (one or more practices missing).

The data were then subjected to standard descriptive analysis. Chi-square statistics were performed to compare the levels of each of the dependent variables with the explanatory variables. A multiple logistic regression model was constructed for each dichotomised outcome variable using all of the explanatory variables which were significant at bivariate analysis at a p-value of 0.05 or less after confirming absence of multi-colleneraity between the independent variables.

The study was approved following ethical review by the Makerere University School of Public Health Institutional Review Board. As per the DSS routines for nonintrusive research verbal consent was sought from each mother after reading to her about and adequately explaining the purpose of the study. Participants were told that they were free not to participate or to withdraw during any stage of the interview. In addition, field assistants were trained to refer sick mothers/newborn babies with problems to the nearby government health facilities where treatment is provided free of charge.

\section{Results}

Of the mothers interviewed about neonatal care practices, only 393 had SES data provided from the previous year's survey. Most of the mothers were young, with $44 \%$ being 25 years or below, and only $27 \%$ were above 30 years (Table 1). The majority of respondents were of the Basoga tribe, were married or living together, and almost three-quarters had only primary or no education. Three-quarters of the mothers were multiparous.

\section{Levels of coverage of essential newborn care practices}

In half the respondents, labour and delivery occurred at night. In general, there were low levels of coverage of the desired practices (Table 2). A total of $46 \%$ of the respondents delivered in the hospital or in a health unit, $26 \%$ delivered in private clinics and $28 \%$ at home or with TBAs. Cord cutting was mostly by use of a razorblade $(67 \%)$ of which $10 \%$ were reused, and only $28 \%$ reported to have used cord scissors. About half of the mothers put substances on the cord (such as powder, surgical spirit, salty water, or lizard droppings).

To keep the babies warm, $86 \%$ were immediately wrapped, but skin-to-skin (STS) care was almost nonexistent (2\%). Early bathing was the norm, with $56 \%$ of the babies bathed within the first 6 hours, $82 \%$ within the first 12 hours and almost all during the first 24 hours. Although all babies were breastfed, only about half were initiated within the first hour of birth, with $41 \%$ initiating within $1-6$ hours. Other feeds besides 
Table 1 Baseline characteristics of the respondents

\begin{tabular}{|c|c|c|}
\hline Characteristics & Total & $\%$ \\
\hline \multicolumn{3}{|l|}{ Maternal Age $n=393$} \\
\hline$<19$ & 35 & 9 \\
\hline $19-25$ & 139 & 35 \\
\hline $26-30$ & 114 & 29 \\
\hline$>30$ & 105 & 27 \\
\hline \multicolumn{3}{|l|}{ Marital status $n=321$} \\
\hline Married/Living together & 291 & 91 \\
\hline Not married & 30 & 9 \\
\hline \multicolumn{3}{|l|}{ Education $n=310$} \\
\hline No education & 39 & 13 \\
\hline Primary & 208 & 67 \\
\hline Secondary & 63 & 20 \\
\hline \multicolumn{3}{|l|}{ Socioeconomic group $n=340$} \\
\hline 1 (Lowest) & 51 & 15 \\
\hline 2 & 67 & 20 \\
\hline 3 & 87 & 26 \\
\hline 4 & 84 & 25 \\
\hline 5 (Highest) & 51 & 15 \\
\hline \multicolumn{3}{|l|}{ Parity $n=393$} \\
\hline 1 & 97 & 25 \\
\hline $2-4$ & 137 & 35 \\
\hline$>4$ & 159 & 40 \\
\hline \multicolumn{3}{|l|}{ No. of ANC visits $n=377$} \\
\hline 1 & 35 & 9 \\
\hline $2-3$ & 225 & 60 \\
\hline$>3$ & 117 & 31 \\
\hline \multicolumn{3}{|c|}{ Trimester of $1^{\text {st }}$ ANC visit $n=278$} \\
\hline 1 & 50 & 13 \\
\hline 2 & 207 & 55 \\
\hline 3 & 121 & 32 \\
\hline \multicolumn{3}{|c|}{ Distance to place of delivery $n=390$} \\
\hline None & 129 & 33 \\
\hline$<5 \mathrm{~km}$ & 200 & 51 \\
\hline$>5 \mathrm{~km}$ & 61 & 16 \\
\hline
\end{tabular}

breast milk, including cow's milk, plain water, sugar or glucose water, gripe water and tea, were given to $35 \%$ of babies in the neonatal period, contrary to recommendations.

Of the twelve practices assessed, we found that neonates in the upper quintile received more interventions/ practices than their counterparts (test for trend $\mathrm{p}<$ 0.001 ). The mean number of practices received was 7.3 (IQR 6-9).

\section{Coverage of newborn interventions across socioeconomic groups}

There was a low level of use of the composite newborn care indices of safe cord care (38\%), good neonatal feeding (57\%) and optimal thermal care (42\%). We found that poor cord care was driven mainly by putting
Table 2 Level of selected care practices during delivery and neonatal period

\begin{tabular}{lcc}
\hline Characteristics & Total & $\%$ \\
\hline Time labour began $\mathrm{n}=356$ & 146 & 42 \\
$\quad$ Day & 205 & 58 \\
$\quad$ Night & & \\
Time of delivery $\mathrm{n}=391$ & 195 & 50 \\
$\quad$ Day & 196 & 50 \\
$\quad$ Night & & \\
Health facility delivery $\mathrm{n}=393$ & 181 & 46 \\
$\quad$ Yes & 212 & 54 \\
$\quad$ No & & \\
Surface of delivery $\mathrm{n}=392$ & 258 & 66 \\
$\quad$ Clean & 134 & 34 \\
$\quad$ Dirty & &
\end{tabular}

Instrument used to cut the cord $\mathrm{n}=391$

Clean

Not clean

$333 \quad 85$

$58 \quad 15$

Material used to tie the cord $n=391$

Clean

Not clean

$387 \quad 99$

Type of instrument used to cut the cord $n=391$

Un used new razor blade

Used razor blade

Scissors

Other/Don't know

What was used to tie the cord $n=391$

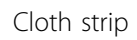

Clean thread

Rubber band

Other/Don't know

What was put on the cord $n=389$

$$
\begin{aligned}
& \text { Nothing } \\
& \text { Medical drugs } \\
& \text { Powder } \\
& \text { Ash } \\
& \text { Salty water } \\
& \text { Other }
\end{aligned}
$$

$\begin{array}{ll}39 & 10.0 \\ 338 & 86.4 \\ 3 & 0.1 \\ 11 & 2.8 \\ & \\ 198 & 51 \\ 11 & 3.0 \\ 87 & 22.2 \\ 3 & 0.8 \\ 43 & 11 \\ 47 & 12\end{array}$

How long after birth baby was breastfed $n=392$

$\begin{array}{lll}\text { Immediately } & 199 & 51 \\ \text { Less than } 6 \text { hours } & 159 & 41 \\ 6-24 \text { hours } & 24 & 6.0 \\ >24 \text { hours } & 10 & 2.0\end{array}$

If at all, bottle fed in neonatal period $\mathrm{n}=391$

Yes

No

How long after birth was baby first bathed $n=244$

Less than 1 hour

$13 \quad 5$

2- 6 hours

$7-12$ hours

13 - 24 hours

$>24$ hours 
Table 2: Level of selected care practices during delivery and neonatal period (Continued)

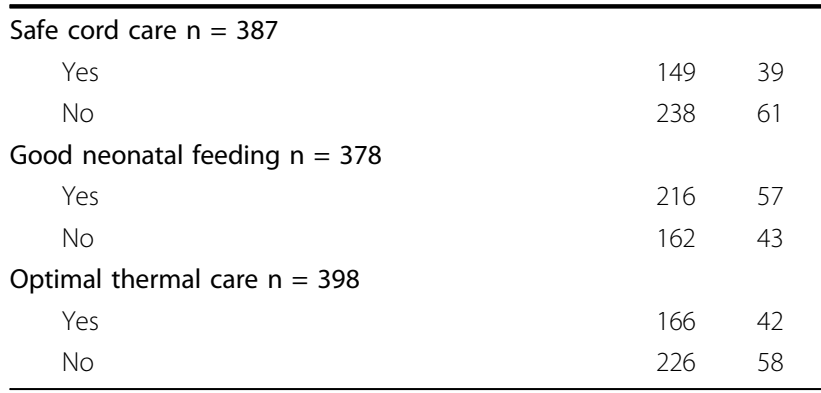

substances on the cord; poor thermal care by early bathing and no STS practice; and poor breastfeeding by giving feeds other than breast milk (results not shown).

\section{Predictors of essential newborn care practices}

Surprisingly, SES was not an independent predictor of any of the composite newborn care practices assessed (Table 3). In bivariate comparisons, significant differences in levels $\left(x^{2}\right.$ Prob $\left.<0.05\right)$ for each of the three outcomes were observed only for clean cord care: parity and the time at which labour had begun. There was no significant association between any of the explanatory variables (including ANC) with either optimal thermal care or good neonatal feeding.

Table 4 shows the independent predictors of safe cord care. Multiparous mothers were less likely to have good cord practices when compared to primiparous (OR 0.5, CI 0.3 - 0.9); and so were mothers whose labour began at night compared to those whose labour began during day time (OR 0.6, CI $0.4-0.9$ ). Although significantly more mothers with high SES delivered in health facilities $(\mathrm{p}<$ 000; results not shown), we found that place of delivery did not predict any of the ENC practices assessed.

\section{Discussion}

The findings, drawn from a population-based survey of all mothers of infants in a demographic surveillance site in two rural districts of Uganda, show that the proportion of newborn babies who receive the essential newborn care practices is generally low and does not differ much by socioeconomic group. We were expecting the newborn practices of mothers of higher SES to be better than those of their counterparts of lower SES, but we found no difference, which was surprising. In addition, none of the explanatory variables we assessed predicted
Table 3 Levels of selected newborn care practices by socio-demographic and antenatal and delivery care factors

\begin{tabular}{|c|c|c|c|c|c|c|}
\hline $\begin{array}{l}\text { Characteristic } \\
\text { Maternal Age }\end{array}$ & \multicolumn{2}{|c|}{$\begin{array}{l}\text { Safe cord } \\
\quad \text { care } \\
\%, \text { p-value }\end{array}$} & \multicolumn{2}{|c|}{$\begin{array}{l}\text { Thermal } \\
\text { care } \\
\%, \text { p-value }\end{array}$} & \multicolumn{2}{|c|}{$\begin{array}{c}\text { Neonatal } \\
\text { feeding } \\
\%, p \text {-value }\end{array}$} \\
\hline$<19$ & 11 & & 8 & & 8 & 0.60 \\
\hline $19-25$ & 32 & 0.04 & 39 & 0.63 & 38 & \\
\hline $26-30$ & 24 & & 26 & & 29 & \\
\hline$>30$ & 33 & & 27 & & 24 & \\
\hline \multicolumn{7}{|l|}{ Parity } \\
\hline 1 & 32 & 0.01 & 25 & 0.77 & 25 & 0.81 \\
\hline $2-4$ & 27 & & 33 & & 37 & \\
\hline$>4$ & 42 & & 42 & & 39 & \\
\hline \multicolumn{7}{|l|}{ Social group } \\
\hline 1 (Lowest) & 14 & & 15 & & 13 & 0.58 \\
\hline 2 & 22 & 0.42 & 23 & 0.66 & 19 & \\
\hline 3 & 24 & & 27 & & 26 & \\
\hline 4 & 28 & & 22 & & 25 & \\
\hline 5 (Highest) & 12 & & 13 & & 18 & \\
\hline \multicolumn{7}{|c|}{ ANC attendance } \\
\hline 1 & 10 & 0.72 & 11 & 0.32 & 8 & 0.82 \\
\hline $2-3$ & 62 & & 55 & & 61 & \\
\hline$>3$ & 28 & & 34 & & 31 & \\
\hline \multicolumn{7}{|c|}{ Time of 1 st visit } \\
\hline $1^{\text {st }}$ trimester & 11 & 0.59 & 12 & 0.97 & 13 & 0.97 \\
\hline $2^{\text {nd }}$ trimester & 55 & & 55 & & 55 & \\
\hline $3^{\text {rd }}$ trimester & 34 & & 33 & & 32 & \\
\hline \multicolumn{7}{|l|}{ Tested for HIV } \\
\hline Yes & 43 & 0.71 & 39 & 0.49 & 38 & 0.13 \\
\hline No & 57 & & 61 & & 62 & \\
\hline \multicolumn{7}{|c|}{ Time labour began } \\
\hline Day & 53 & 0.06 & 44 & 0.22 & 47 & 0.56 \\
\hline Night & 47 & & 56 & & 53 & \\
\hline \multicolumn{7}{|c|}{ Time of delivery } \\
\hline Day & 50 & 0.98 & 48 & 0.44 & 49 & 0.80 \\
\hline Night & 50 & & 52 & & 51 & \\
\hline \multicolumn{7}{|c|}{ Distance to clinic } \\
\hline None & 28 & 0.36 & 35 & 0.78 & 33 & 0.82 \\
\hline$<5 \mathrm{Km}$ & 56 & & 49 & & 52 & \\
\hline $5+\mathrm{Km}$ & 16 & & 16 & & 15 & \\
\hline \multicolumn{7}{|l|}{ Birth prepared } \\
\hline Yes & 87 & 0.67 & 84 & 0.17 & 86 & 0.79 \\
\hline No & 13 & & 16 & & 14 & \\
\hline \multicolumn{7}{|c|}{ Pregnancy counselling } \\
\hline Yes & 96 & 0.64 & 94 & 0.26 & 95 & 0.19 \\
\hline No & 4 & & 6 & & 5 & \\
\hline
\end{tabular}


Table 4 Logistic models with safe cord care practices as dependent variable versus all independent variables that had significant chi-square values in bivariate analysis

\begin{tabular}{ccccc}
\hline Variable & \multicolumn{2}{c}{ Univariate Unadjusted } & \multicolumn{2}{c}{ Multivariate Adjusted } \\
& OR & $\mathbf{9 5 \%} \mathbf{~ C l}$ & OR & $\mathbf{9 5 \% ~ C l}$ \\
\hline $\begin{array}{c}\text { Maternal Age } \\
<19\end{array}$ & 1 & & 1 & \\
$19-25$ & 0.52 & $0.24-1.11$ & 0.68 & $0.31-1.51$ \\
$26-30$ & 0.47 & $0.21-1.03$ & 0.62 & $0.26-1.47$ \\
$>30$ & 0.89 & $0.41-1.93$ & 1.19 & $0.48-2.95$ \\
Parity & & & & \\
1 & 1 & & & \\
$2-4$ & 0.44 & $0.25-0.76$ & 0.45 & $0.25-0.79$ \\
$>4$ & 0.68 & $0.40-1.13$ & 0.57 & $0.30-1.08$ \\
Time labour began & & & \\
Day & 1 & & & \\
Night & 0.66 & $0.44-1.01$ & 0.61 & $0.4 .-0.94$ \\
\hline
\end{tabular}

${ }^{*}$ Adjusted for Maternal age, parity and time labour began

* $p$ for the whole model $=0.003$

any of the assessed composite newborn outcomes. A study in rural India reported that use of antenatal care and skilled attendance at delivery were significantly associated with clean cord care and early breastfeeding, but not with thermal care [14].

We found that the low level of safe cord care was due mainly to putting substances on the cord, that poor thermal care was mainly due to early bathing, and that poor breastfeeding was primarily due to giving feeds other than breast milk. Although not recommended, about half the respondents applied substances such as powder, salty water, and lizard droppings to the umbilical cord. Clean cord care is very important in preventing early neonatal infections [5]. We thus found cord care to be wanting. In the absence of supplies in health facilities, cord cutting was done mainly with razorblades, some of which were not clean - a dangerous practice for both mother and newborn given especially that tetanus is still a problem in this area [15] as well as the high prevalence of HIV in pregnancy (6.5\%) in Uganda [16]. Mothers apply substances to the cord for several reasons, including to "help the cord heal fast" so that they can go back to their domestic chores [17]. Similar findings have been reported from studies elsewhere in Uganda [18] and in Tanzania [19].

Regarding prevention of hypothermia, we found that STS care was generally not practiced. Currently, STS care is recommended for all babies [20]. In addition, whereas it is recommended that babies should be bathed no earlier than 24 hours after birth, we found instead that most were bathed within the first 12 hours, and almost all within 24 hours of birth. Maintaining good thermal care at birth is crucial for preventing hypothermia, hypoglycemia and neonatal infections. Indeed, studies in Uganda have shown that even if it is a tropical country, hypothermia at birth is common [21,22].

Our findings indicate that although almost all mothers breastfed their babies, about half of the infants were not breastfed within the first one hour as is recommended [23], thereby putting these neonates at an increased risk for death [24]. In addition, more than one-third of respondents reported that they gave feeds other than breast milk in the neonatal period. A study by Engebretsen et al. conducted in eastern Uganda [25] found that only $7 \%$ of infants were exclusively breastfed by age three months. In other words, both her study and ours show that as early as the neonatal period, over one-third of infants are not having exclusive breastfeeding.

The proportion of newborn babies receiving the recommended ENC practices was low but similar among both the poor and the least poor. The finding that there is no inequity in newborn care practices was not expected, and we found no literature describing it. Usually, access to childhood interventions is lowest among the poorest and highest among the least poor [11]. Many studies have described inequities in access to childhood interventions $[11,26,27]$. However, we found only a few studies which have described inequities in newborn health $[28,29]$. In a study in rural India, Baqui et al. examined whether NGO facilitation of the government's community-based health programme improved the equity of maternal and newborn health and found that improvement in equity was most pronounced in household practices, but inequity was still marked in health care utilisation [29]. In another study, Fenn and colleagues assessed within-country inequities of neonatal mortality and coverage of key interventions using wealth quintiles in eight low income countries [28]. They found that access to interventions was directly related to socioeconomic level, with poorer mothers having reduced access to interventions compared with those in the wealthier groups. However, their findings are based on individual practices whose coverage may be high; and yet when combined into a composite measure may be quite low, as demonstrated in this study.

We hypothesise that our findings may have another explanation. Due to increasing socioeconomic development, a number of mothers are putting powder on the cord, using a bottle to feed the baby, and mixing/replacing breastfeeding with various substitutes. We describe this phenomenon as "modernistic" and suggest that there may be a newborn "practice transition" to practices wrongly perceived to be safe. The Uganda Demographic Health Survey [8] and a study in western Uganda found that educated mothers were more prone to use pre-lacteals [30]. Other studies have also demonstrated that socioeconomic status has little effect on neonatal practices such as breastfeeding practices [31]. 
Why are these newborn care practices low across SES? We have two possible explanations: 1 . Since newborn care is a neglected area, there are currently no effective programmes promoting newborn care practices either in health facilities or at community level, and the low proportion of newborn babies with appropriate newborn care practices could thus be a case of lack of adequate knowledge and exposure to messages [30]; 2. It could be that the population we studied is relatively homogenous and the absolute differences are generally not significant between the upper and lower quintiles [32], (e.g. most women had only primary education).

These findings have important programme and policy implications if neonatal health is to be improved in Uganda and other low income countries within the context of changing demographics, including urbanisation. Since the ENC practices were inadequate among both the poor and least poor, to ensure equity programme implementation should focus on universal coverage and not simply target the poorest members of the community [33]. In addition, the possibility of change in newborn care practices needs to be watched, including aspects of safety to a newborn baby. Finally, we recommend that evaluation of newborn care practices should include both the individual but also the composite practices. Coverage of individual practices may be high, and yet when combined into a composite measure may be quite low.

The results presented here should be interpreted with some caution. The survey was done in only one region of Uganda. However, the study setting did have relatively good physical access to health facilities than would be expected for most areas of rural Uganda, meaning that newborn care practices elsewhere may not be much better than those reported here. In addition, we were not able to verify the actual practices as data were collected through recall, and we excluded mothers who had a stillbirth or a newborn that had died. To minimise recall bias, we limited our interviews to only mothers with babies up to four months. Similar studies report recall up to one year after birth $[14,34]$.

\section{Conclusions}

Both demand and supply side strategies are needed to ensure that these simple but essential interventions are universally promoted within the continuum of care at scale irrespective to socioeconomic status in order to improve newborn survival in Uganda and in similar settings. The level of coverage of essential newborn care practices in this setting is generally poor and does not differ by socioeconomic grouping when assessed as composite practices. Despite being policy, most neonatal interventions are not reaching newborns, suggesting a "policy-to-practice gap". A newborn care "practice transition" in which "suboptimal" practices are being replaced with "modernistic" practices may be underway, requiring attention and action.

\section{Acknowledgements}

We thank the study participants, research assistants, staff of the Makerere University-operated Iganga-Mayuge Demographic Surveillance Site (in particular Daniel Kadobera, Dorean Nabukalu, Judith Kaija and Edward Galiwango, for managing data collection, compilation and entry), and the Study Policy Advisory Group (Iganga and Mayuge Districts, WHO/Uganda UNICEF/Uganda, SNL/Uganda and $\mathrm{MOH}$ ). We acknowledge useful comments on the manuscript from Dr. Joy Lawn and Ms Kate Kerber, Pauline Binder for language editing and to Geoffrey Namara of MRC Uganda for statistical advice. We are grateful to InDepth Network for providing the DSS platform for research and for technical support to the DSS.

\section{Author details}

${ }^{1}$ Makerere University School of Public Health, Kampala, Uganda. ${ }^{2}$ Global Health, Department of Public Health Sciences, Karolinska Institutet, Stockholm, Sweden. ${ }^{3}$ International Maternal and Child Health, Department of Women's and Children's Health, Uppsala University, Uppsala, Sweden.

${ }^{4}$ Medical Management Centre, Karolinska Institutet, Stockholm, Sweden.

\section{Authors' contributions}

PW, SP, GT and GWP conceived the study. PW, SP, GT and GWP took part in designing the study, in tool development, analysis and manuscript writing. PW supervised the field work, and led the analysis and drafting of the manuscript. All authors approved the final manuscript.

\section{Competing interests}

The authors declare that they have no competing interests.

Received: 16 July 2009

Accepted: 23 February 2010 Published: 23 February 2010

\section{References}

1. Bryce J, Daelmans B, Dwivedi A, Fauveau V, Lawn JE, Mason E, Newby H, Shankar A, Starrs A, Wardlaw T: Countdown to 2015 for maternal, newborn, and child survival: the 2008 report on tracking coverage of interventions. Lancet 2008, 371(9620):1247-1258.

2. Lawn JE, Cousens S, Zupan J: 4 million neonatal deaths: when? Where? Why?. Lancet 2005, 365(9462):891-900.

3. Black RE, Morris SS, Bryce J: Where and why are 10 million children dying every year?. Lancet 2003, 361(9376):2226-2234.

4. Marsh DR, Darmstadt GL, Moore J, Daly P, Oot D, Tinker A: Advancing newborn health and survival in developing countries: a conceptual framework. J Perinatol 2002, 22(7):572-576.

5. Darmstadt GL, Bhutta ZA, Cousens S, Adam T, Walker N, de Bernis L: Evidence-based, cost-effective interventions: how many newborn babies can we save?. Lancet 2005, 365(9463):977-988.

6. Kerber KJ, de Graft-Johnson JE, Bhutta ZA, Okong P, Starrs A, Lawn JE: Continuum of care for maternal, newborn, and child health: from slogan to service delivery. Lancet 2007, 370(9595):1358-1369.

7. Tinker A, ten Hoope-Bender P, Azfar S, Bustreo F, Bell R: A continuum of care to save newborn lives. Lancet 2005, 365(9462):822-825.

8. Uganda Demographic and Health Survey 2006 Calverton, Maryland, USA: Uganda Bureau of Statistics Entebbe (UBOS) and ORC Macro 2006.

9. Ministry of Health: Uganda Health Sector Strategic Plan II 2005/6-2009/2010. Kampala 2005.

10. Hosseinpoor AR, Mohammad K, Majdzadeh R, Naghavi M, Abolhassani F, Sousa A, Speybroeck N, Jamshidi HR, Vega J: Socioeconomic inequality in infant mortality in Iran and across its provinces. Bull World Health Organ 2005, 83(11):837-844

11. Victora CG, Fenn B, Bryce J, Kirkwood BR: Co-coverage of preventive interventions and implications for child-survival strategies: evidence from national surveys. Lancet 2005, 366(9495):1460-1466.

12. Cronbach $L$ : Coefficient alpha and the internal structure of tests. Psychometrika 1951, 16(3):297-334. 
13. Filmer D, Pritchett $L H$ : Estimating wealth effects without expenditure data-or tears: an application to educational enrollments in states of India. Demography 2001, 38(1):115-132.

14. Baqui AH, Williams EK, Darmstadt GL, Kumar V, Kiran TU, Panwar D, Sharma RK, Ahmed S, Sreevasta V, Ahuja R, et al: Newborn care in rural Uttar Pradesh. Indian J Pediatr 2007, 74(3):241-247.

15. Gitta SN, Wabwire-Mangen F, Kitimbo D, Pariyo G: Risk factors for neonatal tetanus-Busoga region, Uganda, 2002-2003. MMWR Morb Mortal Wkly Rep 2006, 55(Suppl 1):25-30.

16. Baryarama F, Bunnell RE, Montana L, Hladik W, Opio A, Musinguzi J, Kirungi W, Waswa-Bright L, Mermin JH: HIV prevalence in voluntary counseling and testing centers compared with national HIV serosurvey data in Uganda. J Acquir Immune Defic Syndr 2008, 49(2):183-189.

17. Waiswa P, Kemigisa M, Kiguli J, Naikoba S, Pariyo GW, Peterson S: Acceptability of evidence-based neonatal care practices in rural Uganda - implications for programming. BMC Pregnancy Childbirth 2008, 8:21.

18. Tann CJ, Kizza M, Morison L, Mabey D, Muwanga M, Grosskurth H, Elliott AM: Use of antenatal services and delivery care in Entebbe, Uganda: a community survey. BMC Pregnancy Childbirth 2007, 7:23.

19. Mrisho M, Schellenberg JA, Mushi AK, Obrist B, Mshinda H, Tanner M, Schellenberg D: Understanding home-based neonatal care practice in rural southern Tanzania. Trans R Soc Trop Med Hyg 2008, 102(7):669-678.

20. Darmstadt GL, Kumar V, Yadav R, Singh V, Singh P, Mohanty S, Baqui AH, Bharti N, Gupta S, Misra RP, et al: Introduction of community-based skinto-skin care in rural Uttar Pradesh, India. J Perinatol 2006, 26(10):597-604.

21. Bergstrom A, Byaruhanga R, Okong P: The impact of newborn bathing on the prevalence of neonatal hypothermia in Uganda: a randomized, controlled trial. Acta Paediatr 2005, 94(10):1462-1467.

22. Byaruhanga $R$, Bergstrom A, Okong P: Neonatal hypothermia in Uganda: prevalence and risk factors. J Trop Pediatr 2005, 51(4):212-215.

23. World Health Organization: Essential newborn care: a report of a technical working group. Geneva 1996.

24. Edmond KM, Zandoh C, Quigley MA, Amenga-Etego S, Owusu-Agyei S, Kirkwood BR: Delayed breastfeeding initiation increases risk of neonatal mortality. Pediatrics 2006, 117(3):e380-386.

25. Engebretsen IM, Wamani H, Karamagi C, Semiyaga N, Tumwine J, Tylleskar T: Low adherence to exclusive breastfeeding in Eastern Uganda: a community-based cross-sectional study comparing dietary recall since birth with 24-hour recall. BMC Pediatr 2007, 7:10.

26. Gwatkin DR, Rutstein S, Johnson K, Suliman E, Wagstaff A, Amouzou A: Socio-economic differences in health, nutrition, and population within developing countries: an overview. Niger J Clin Pract 2007, 10(4):272-282.

27. Schellenberg JA, Victora CG, Mushi A, de Savigny D, Schellenberg D, Mshinda $\mathrm{H}$, Bryce J: Inequities among the very poor: health care for children in rural southern Tanzania. Lancet 2003, 361(9357):561-566.

28. Fenn B, Kirkwood BR, Popatia Z, Bradley DJ: Inequities in neonatal survival interventions: evidence from national surveys. Arch Dis Child Fetal Neonatal Ed 2007, 92(5):F361-366.

29. Baqui AH, Rosecrans AM, Williams EK, Agrawal PK, Ahmed S, Darmstadt GL, Kumar V, Kiran U, Panwar D, Ahuja RC, et al: NGO facilitation of a government community-based maternal and neonatal health programme in rural India: improvements in equity. Health Policy Plan 2008, 23(4):234-243.

30. Wamani H, Astrom AN, Peterson S, Tylleskar T, Tumwine JK: Infant and young child feeding in western Uganda: knowledge, practices and socio-economic correlates. J Trop Pediatr 2005, 51(6):356-361.

31. Shirima R, Gebre-Medhin M, Greiner T: Information and socioeconomic factors associated with early breastfeeding practices in rural and urban Morogoro, Tanzania. Acta Paediatr 2001, 90(8):936-942.

32. Vyas S, Kumaranayake L: Constructing socio-economic status indices: how to use principal components analysis. Health Policy Plan 2006, 21(6):459-468.

33. Victora CG, Wagstaff A, Schellenberg JA, Gwatkin D, Claeson M, Habicht JP: Applying an equity lens to child health and mortality: more of the same is not enough. Lancet 2003, 362(9379):233-241.

34. Osrin D, Tumbahangphe KM, Shrestha D, Mesko N, Shrestha BP, Manandhar MK, Standing H, Manandhar DS, Costello AM: Cross sectional, community based study of care of newborn infants in Nepal. BMJ 2002, 325(7372):1063.

\section{Pre-publication history}

The pre-publication history for this paper can be accessed here:http://www. biomedcentral.com/1471-2393/10/9/prepub

doi:10.1186/1471-2393-10-9

Cite this article as: Waiswa et al:: Poor newborn care practices - a population based survey in eastern Uganda. BMC Pregnancy and

Childbirth 2010 10:9.

\section{Submit your next manuscript to BioMed Central and take full advantage of:}

- Convenient online submission

- Thorough peer review

- No space constraints or color figure charges

- Immediate publication on acceptance

- Inclusion in PubMed, CAS, Scopus and Google Scholar

- Research which is freely available for redistribution

Submit your manuscript at www.biomedcentral.com/submit
Biomed Central 